\title{
Psychological Results of 438 Patients with persisting Gastroesophageal Reflux Disease Symptoms by Symptom Checklist 90-Revised Questionnaire
}

\author{
${ }^{1}$ Xia Chen, ${ }^{1}$ Ping Li, ${ }^{1}$ Fei Wang, ${ }^{1}$ Guozhong Ji, ${ }^{1}$ Lin Miao, ${ }^{1}$ Sihong You \\ ${ }^{1}$ Department of Gastroenterology, The Second Affiliated Hospital of Nanjing Medical University, Nanjing, Jiangsu, China
}

\begin{abstract}
Aims and objectives: Gastroesophageal reflux disease (GERD) affects mental state and social activities. On the contrary, mental disorders may also play a crucial role in GERD symptoms. The purpose of the study was to analyze the data of Symptom Checklist 90-Revised (SCL-90-R) questionnaire from patients with persisting GERD and to explore the impact of psychological factors on them.
\end{abstract}

Materials and methods: The patients accepted SCL-90-R questionnaire survey, following endoscopy, high-resolution manometry (HRM), and ambulatory impedance- $\mathrm{pH}$ monitoring. Based on these results, we divided patients into different groups. The result of SCL-90-R was also compared with degree of acid reflux, symptoms, symptom duration, and gender.

Results: The data from 438 patients were analyzed. All patients were divided into reflux esophagitis (RE; 63, 14.38\%); nonerosive gastroesophageal reflux disease (NERD; 106, 24.20\%); functional heartburn ( $\mathrm{FH} ; 123,28.08 \%$ ), hypersensitive esophagus (HE; $67,15.29 \%)$, diffuse esophageal spasm (DES; 5: 1.14\%), hypertensive (10, 3.42\%); weak peristalsis (14, 3.20\%); achalasia $(50,11.42 \%)$. There were significant differences between different groups regarding depression (DEP), anxiety (ANX), paranoid ideation (PAR), and psychoticism (PSY). The patients with $\geq 2$ years with GERD presented with increased scores in DEP, ANX, and PSY. Women had dramatically higher scores than men in each domain $(p<0.05)$.

Conclusion: Data have shown that GERD patients exhibit differential levels of psychological symptoms. Long duration of GERD was related to typical plus atypical symptoms and females seem to be more prone to develop psychological disorders.

Keywords: Gastroesophageal reflux disease, High-resolution manometry, Impedance-pH monitoring, Refractory proton pump inhibitor symptoms, Symptom checklist 90-Revised questionnaire.

How to cite this article: Chen X, Li P, Wang F, Ji G, Miao L, You S. Psychological Results of 438 Patients with persisting Gastroesophageal Reflux Disease Symptoms by Symptom Checklist 90-Revised Questionnaire. Euroasian J Hepato-Gastroenterol 2017;7(2):117-121.

Source of support: Nil

Conflict of interest: None

\section{INTRODUCTION}

Due to several factors, the incidence of GERD has been increasing in Asian and Western countries. ${ }^{1,2}$ Therapeutic strategy for GERD mainly involves the use of proton pump inhibitors (PPIs). Despite treatment with standard PPI dose, unfortunately, 20 to $30 \%$ of patients still suffer from troublesome GERD symptoms. ${ }^{3}$ Persisting GERD symptoms cause discomfort, impair quality of life, and affect mental state and social activities. Likewise, the subsequent development of mental disorders, such as ANX, and depressive symptoms also plays a crucial role on GERD symptom deterioration and has a negative effect on people's quality of life. ${ }^{4}$

As a self-report questionnaire may be able to provide multidimensional and normative data, the SCL-90-R is widely used for all psychiatric patients. Some medical groups applied SCL-90-R to evaluate the psychological state of patients with chronic diseases. 5 ,6 Previous studies suggest that the SCL-90-R could be valuable in evaluating psychological factors and, therefore, recommend it for psychosocial investigation in varied disease clinical practice. ${ }^{7-9}$ However, data from patients Nanjing, Jiangsu, China, Phone: +862558509932, e-mail: xiac6686@gmail.com 
with persisting refractory GERD symptom based on SCL90-R questionnaire have not been properly evaluated.

This study focused on the psychological state of refractory GERD patients using SCL-90-R. We intended to find the differences between several conditions of refractory GERD symptom and to assess if SCL-90-R would be a new, simple method for screening patients with GERD in a community hospital. Consequently, it may be helpful for gastroenterologists to choose relatively precise diagnostic approaches.

\section{MATERIALS AND METHODS}

The target patients were all with persisting GERD symptoms after 8-week trial of once-daily PPI therapy from October 2010 to November 2015.

Exclusion criteria included previous psychopathological disease; previous digestive disease surgery; organic disease in digestive tract; severe comorbidity; any type of cancer; currently taking psychological drugs; and diagnosis of functional gastrointestinal disorders (FGIDs).

The tests, such as SCL-90-R, ${ }^{10}$ upper gastrointestinal endoscopy, and HRM (Given Imaging, Los Angeles, California) were accomplished; 24-hour impedance-pH monitoring (Given Imaging, Los Angeles, California) was done. Data of HRM and impedance-pH monitoring analysis were performed using software (Mano View software; Sierra Scientific Instrument Inc, Los Angeles, California).

The SCL-90-R consists of 90 items, evaluating psychopathological and somatic status on a 4-point scale. The scale ranges from 0 (absence of the symptom) to 4 (maximum disturbance). These items are divided into nine scale markers as: DEP; somatization (SOM); ANX; obsessive-compulsive behavior (O-C); hostility (HOS); interpersonal sensitivity (I-S); phobic anxiety (PHOB); PSY; and PAR. Every dimension includes 6 to 13 questions. The score on each dimension represents the mean score of the dimension and directly reflects the severity of the mental health problem. Subscale scores $\geq 2$ were suggestive of potential mental health issues. The global severity index (GSI) indicates the mean score of 90 items. $^{11}$

Based on endoscopy, HRM, and impedance-pH monitoring, we divided patients into subgroups, such as NERD, RE, FH, HE, DES, hypertensive, weak peristalsis, and achalasia. The diagnosis was made and classified according to the Chicago classification and previously published criteria. ${ }^{12,13}$

\section{STATISTICAL ANALYSIS}

Data analysis was performed independently by two investigators unaware of the status of individuals.
The data were shown as mean \pm standard deviation. Analysis of variance for continuous variables and Pearson's chi-square test for categorical variables using Statistical Package for the Social Sciences version 13.0 was accomplished. A p-value $<0.05$ was significant and all $p$ values were two-sided.

\section{RESULTS}

\section{Clinical Characteristics}

A total of 438 patients (137 male, 301 female, age 51.42 \pm 17.30 years) were analyzed in this study (Table 1 ). Symptom duration of these patients was $4.02 \pm 1.45$ years. There were 271 (61.87\%) patients with heartburn and 239 (54.57\%) with regurgitation, 189 (43.15\%) with retrosternal discomfort and pain (Table 1). All patients were divided into RE (63, 14.38\%), NERD (106, 24.20\%), FH (123, 28.08\%), HE $(67,15.29 \%)$, DES $(5,1.14 \%)$, hypertensive $(10,3.42 \%)$, weak peristalsis $(14,3.20 \%)$, achalasia $(50,11.42 \%)$.

Table 1: Demographics and clinical characteristics

\begin{tabular}{|c|c|c|}
\hline Characteristics $(n=438)$ & $n$ & $\%$ \\
\hline Age (years) & $51.42 \pm 17.30$ & \\
\hline Range & $19-83$ & \\
\hline \multicolumn{3}{|l|}{ Gender } \\
\hline Male & 137 & 31.28 \\
\hline Female & 301 & 68.72 \\
\hline BMI & $23.42 \pm 10.37$ & \\
\hline $\mathrm{RE}$ & 63 & 14.38 \\
\hline NERD & 106 & 24.20 \\
\hline $\mathrm{HE}$ & 123 & 28.08 \\
\hline $\mathrm{FH}$ & 67 & 15.29 \\
\hline DES & 5 & 1.14 \\
\hline Hypertensive & 10 & 3.42 \\
\hline Weak peristalsis & 14 & 3.20 \\
\hline Achalasia & 49 & 11.19 \\
\hline Smoking & 142 & 32.42 \\
\hline Alcohol consumption & 145 & 33.10 \\
\hline \multicolumn{3}{|l|}{ Drug history } \\
\hline Calcium ion antagonist & 179 & 40.87 \\
\hline Aspirin & 153 & 34.93 \\
\hline Hypnotic drug & 51 & 11.64 \\
\hline Past medical history & 253 & \\
\hline \multicolumn{3}{|l|}{ Symptom } \\
\hline Duration (years) & $4.02 \pm 1.45$ & \\
\hline Heartburn & 271 & 61.87 \\
\hline Regurgitation & 239 & 54.57 \\
\hline Retrosternal discomfort and pain & 189 & 43.15 \\
\hline Cough & 74 & 16.89 \\
\hline Asthma & 19 & 4.34 \\
\hline Hoarseness & 34 & 7.76 \\
\hline Throat discomfort & 195 & 44.52 \\
\hline Foreign body sensation in throat & 113 & 25.80 \\
\hline Globus sensation & 63 & 14.38 \\
\hline Belching & 204 & 46.58 \\
\hline Dysphagia & 152 & 34.70 \\
\hline $\begin{array}{l}\text { Epigastric pain and epigastric } \\
\text { discomfort }\end{array}$ & 204 & 46.58 \\
\hline
\end{tabular}

BMI: Body Mass Index 
Psychological Results of 438 Patients with persisting GERD Symptoms

\begin{tabular}{|c|c|c|c|c|c|c|c|c|}
\hline & $\begin{array}{l}R E \\
(n=63)\end{array}$ & $\begin{array}{l}H E \\
(n=67)\end{array}$ & $\begin{array}{l}F H \\
(n=123)\end{array}$ & $\begin{array}{l}\text { NERD } \\
(n=106)\end{array}$ & $\begin{array}{l}\text { Achalasia } \\
(n=50)\end{array}$ & $\begin{array}{l}\text { Hypertensive } \\
(n=10)\end{array}$ & $\begin{array}{l}D E S \\
(n=5)\end{array}$ & $\begin{array}{l}\text { Weak } \\
(n=14)\end{array}$ \\
\hline SOM & $1.39 \pm 0.58$ & $1.46 \pm 0.62$ & $1.57 \pm 0.67$ & $1.40 \pm 0.62$ & $1.54 \pm 0.66$ & $1.66 \pm 0.72$ & $1.20 \pm 0.59$ & $1.46 \pm 0.90$ \\
\hline $\mathrm{O}-\mathrm{C}$ & $1.50 \pm 0.54$ & $1.42 \pm 0.64$ & $1.55 \pm 0.63$ & $1.50 \pm 0.63$ & $1.62 \pm 0.73$ & $1.39 \pm 0.56$ & $1.94 \pm 0.70$ & $1.62 \pm 0.73$ \\
\hline I-S & $1.43 \pm 0.67$ & $1.35 \pm 0.66$ & $1.38 \pm 0.57$ & $1.40 \pm 0.59$ & $1.48 \pm 0.71$ & $1.57 \pm 0.75$ & $1.20 \pm 0.59$ & $1.60 \pm 0.69$ \\
\hline DEP* & $1.48 \pm 0.64$ & $1.51 \pm 0.65$ & $1.77 \pm 0.59$ & $1.80 \pm 0.59$ & $1.76 \pm 0.66$ & $1.27 \pm 0.54$ & $1.65 \pm 0.67$ & $1.61 \pm 0.81$ \\
\hline ANX* & $1.50 \pm 0.60$ & $1.46 \pm 0.70$ & $1.69 \pm 0.62$ & $1.70 \pm 0.53$ & $1.87 \pm 0.66$ & $1.34 \pm 0.57$ & $1.57 \pm 1.06$ & $1.72 \pm 0.73$ \\
\hline HOS & $1.44 \pm 0.56$ & $1.40 \pm 0.62$ & $1.40 \pm 0.61$ & $1.39 \pm 0.67$ & $1.35 \pm 0.56$ & $1.40 \pm 0.84$ & $1.20 \pm 0.59$ & $1.51 \pm 0.75$ \\
\hline PHOB & $1.48 \pm 0.64$ & $1.47 \pm 0.62$ & $1.42 \pm 0.58$ & $1.47 \pm 0.64$ & $1.56 \pm 0.68$ & $1.20 \pm 0.57$ & $1.57 \pm 1.06$ & $1.37 \pm 0.56$ \\
\hline PAR* $^{*}$ & $1.27 \pm 0.49$ & $1.16 \pm 0.47$ & $1.27 \pm 0.47$ & $1.32 \pm 0.57$ & $1.12 \pm 0.44$ & $0.96 \pm 0.36$ & $0.56 \pm 0.51$ & $1.36 \pm 0.51$ \\
\hline $\mathrm{PSY}^{*}$ & $1.26 \pm 0.47$ & $1.31 \pm 0.53$ & $1.23 \pm 0.51$ & $1.27 \pm 0.50$ & $1.59 \pm 0.57$ & $1.58 \pm 0.60$ & $1.67 \pm 0.48$ & $1.51 \pm 0.50$ \\
\hline $\mathrm{GSI}^{*}$ & $1.04 \pm 0.41$ & $1.01 \pm 0.42$ & $1.02 \pm 0.38$ & $1.18 \pm 0.38$ & $1.07 \pm 0.44$ & $1.17 \pm 0.47$ & $0.94 \pm 0.43$ & $1.11 \pm 0.44$ \\
\hline
\end{tabular}

${ }^{*} p<0.05$ between groups

\section{SCL-90-R Questionnaire Survey}

We investigated the scores of SCL-90-R in different groups (Table 2). The results indicated that the scores had significant differences between various groups as shown by DEP, ANX, PAR, PSY, and GSI. In DEP domain, the score in RE group was less than that in NERD, FH, achalasia groups $(\mathrm{p}<0.05)$; the score in NERD was more than in HE and hypertensive groups $(\mathrm{p}<0.05)$; the score in $\mathrm{FH}$ was more than in hypertensive and HE $(\mathrm{p}<0.05)$; the score in achalasia was more than in HE as well as hypertensive groups $(p<0.05)$. About ANX domain, we found RE group had less score than in NERD and achalasia groups $(\mathrm{p}<0.05)$; NERD group had more than HE group ( $\mathrm{p}<0.05)$; FH group had more score than HE group $(\mathrm{p}<0.05)$; achalasia had more score than HE and hypertensive groups $(\mathrm{p}<0.05)$. For PSY, the score of achalasia group showed higher level than RE, NERD, FH, and HE groups $(\mathrm{p}<0.05)$; the score of FH group was more than hypertensive group $(\mathrm{p}<0.05)$. For PAR, NERD group had more score than $\mathrm{HE}$, hypertensive and achalasia groups $(\mathrm{p}<0.05)$, and hypertensive group had more score than DES group

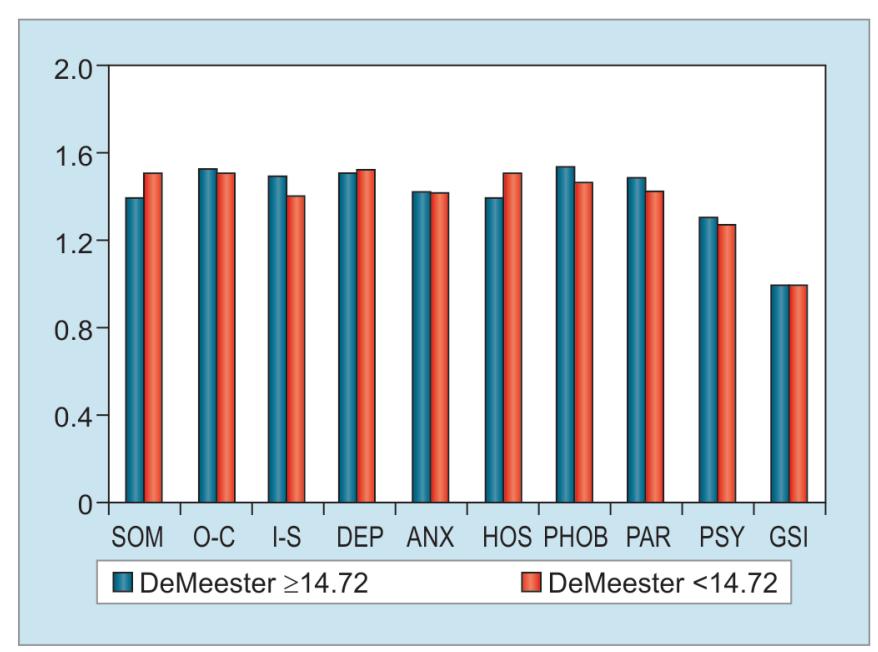

Graph 1: SCL-90-R scores based on DeMeester value. No differences were detected in nine domains and GSI between DeMeester value $\geq 14.72$ and DeMeester value $<14.72$ $(p<0.05)$. According to the result of GSI domain, the data revealed that the level of NERD was higher than $\mathrm{RE}, \mathrm{FH}$, and HE groups $(\mathrm{p}<0.05)$.

The nine domains with DeMeester pathological $(\geq 14.72, \mathrm{n}=114)$ and normal $(<14.72, \mathrm{n}=245)$ values showed no statistical differences ( $p>0.05$; Graph 1). However, we found statistically significant differences between the patients with less duration of GERD symptoms ( $<2$ years, $n=95$ ) with those with prolonged GERD duration ( $\geq 2$ years, $n=343$ ). The patients with more duration presented more scores in DEP, ANX, and PSY $(\mathrm{p}<0.05$; Graph 2). But the score of PAR was lower in $\geq 2$ years group $(\mathrm{p}<0.05)$. Subjects with GERD typical plus atypical symptoms $(n=253)$ had higher scores compared with subjects only with typical symptoms $(n=185)$ in SOM, ANX, PSY, and GSI ( $p<0.05$; Graph 3). Compared with gender, women had dramatically higher scores than men in these nine domains (all $\mathrm{p}<0.05$; Graph 4).

\section{DISCUSSION}

Psychosocial factors are able to exert influence on deterioration of disease, symptoms, responses to treatment,

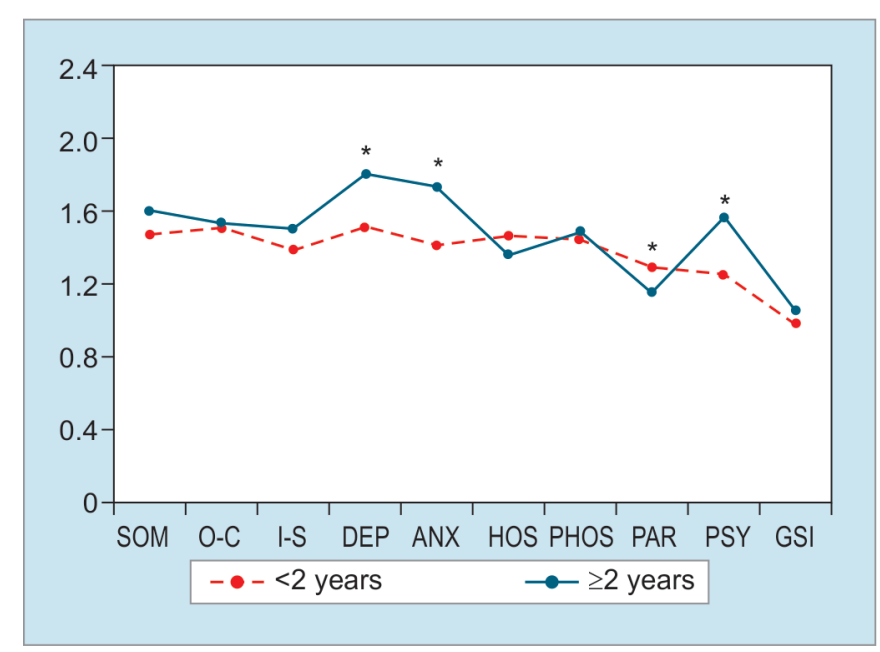

Graph 2: SCL-90-R scores depending on symptom duration. Significant differences were seen in DEP, ANX, PAR, and PSY domains. ${ }^{*} p<0.05$ 


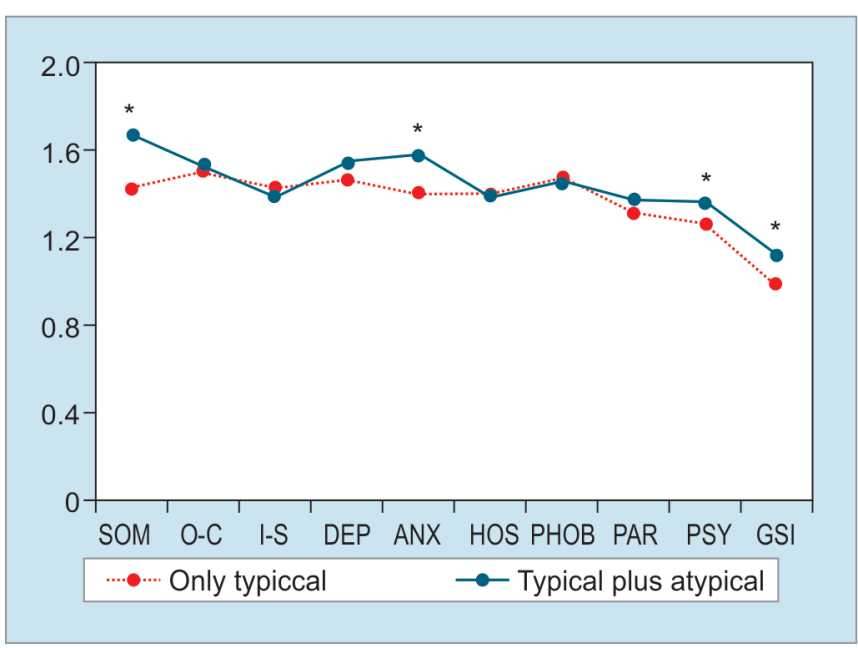

Graph 3: SCL-90-R scores based on symptom. Significant differences were seen in SOM, ANX, and PSY domains and GSI. ${ }^{*} p<0.05$

and the quality of life. Researchers evaluated the psychological status of patients with chronic disease using SCL-90-R questionnaire. A link of GERD and psychopathological features has already been demonstrated by several studies. ${ }^{14,15}$ We analyzed the data from the patients with refractory GERD symptoms in order to acquire their psychological characteristics, which may be helpful for making diagnosis and clinical strategy.

In this study, O-S and I-S, which are stable personality characters and are referred as personality, were not found to be statistically significant between these patients. But, differences were found regarding DEP, ANX, PAR, PSY, and GSI domains. The results suggest that the psychological status perhaps does not have close relationship with acid reflux. Remarkably, achalasia showed more psychological factors. Considering that achalasia is an unknown congenital disease, those factors will certainly exist because of refractory GERD symptoms. They probably are the result of symptoms from which patients have suffered for a quite long duration. Taken together, it appears that psychological factors will have a distinct effect on chronic diseases. ${ }^{5,16,17}$

With our other comparison results based on DeMeester value, we did not find difference between pathological and normal acid reflux. This strongly supports our suggestion that psychological status does not relate to acid reflux again. Possible reason is that the universal usage of PPIs has effectively controlled acid reflux; therefore, this makes patients benefit from reducing mental stress.

A large number of previous studies have revealed that patients with typical symptoms are apt to suffer from atypical GERD symptoms and FGID symptoms. ${ }^{18,19}$ Also, there is always an overlap between reflux symptoms, irritable bowel syndrome, and functional dyspepsia. The atypical GERD symptoms are closely related to the

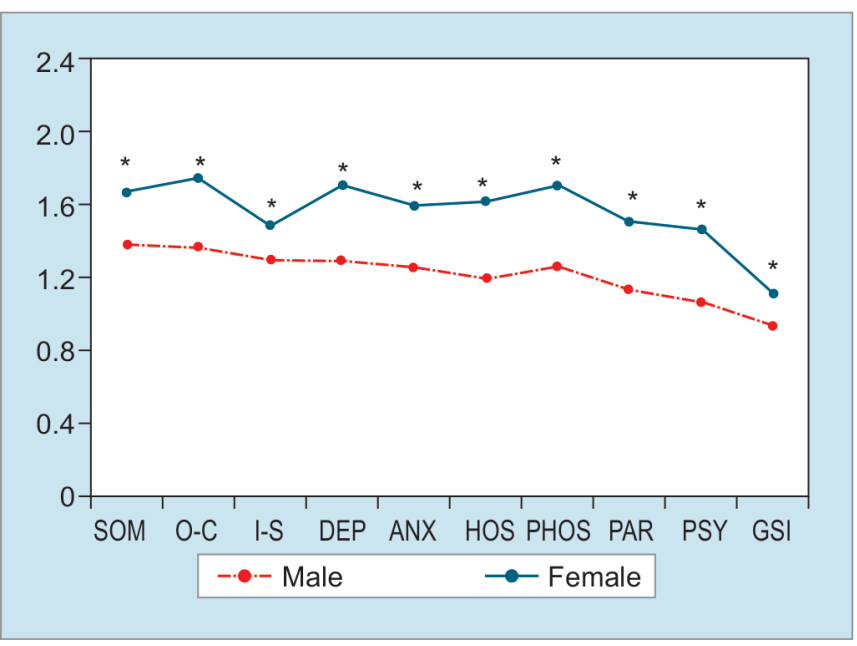

Graph 4: SCL-90-R scores based on gender. The scores of females were significantly more than those of males in all domains and GSI. * $p<0.05$

typical GERD symptoms. ${ }^{20}$ Unlike the study of Lee et $\mathrm{l}^{21}$ that showed that patients with symptomatic RE had more scores than patients with asymptomatic RE on all dimensions of SCL-90-R, we chose patients only with typical GERD symptom to compare with those with typical plus atypical GERD symptom. Our aim was to acquire more precise information about the relationship between mental disorder and GERD symptom.

The analysis of symptom duration in this study showed that the patients with more duration had more problems regarding DEP, ANX, and PSY. Considering gender difference, we investigated the data divided by females and males. Our results are consistent with those of Núñez-Rodríguez and Miranda Sivelo ${ }^{17}$ that women had dramatically higher scores than men in these nine domains by SCL-90-R. Due to more and more researchers paying attention to gender difference in chronic disease development, ${ }^{22-24}$ we assume that the difference between females and males is worthy of further investigations.

Regarding the measurement of mental disorders with SCL-90-R, some limitations are also prevailing in this study. The processes including interviewing, diagnosing, and rating were done by experts in our gastroenterology department. Although our research team acquired the assistance of psychologists, the results were likely to have a little bias. Moreover, the samples in this study were regional instead of a being nationally representative. Differences across cities and countries may occur due to differences in sociodemographics. Large-scale multicenter studies need to be carried out in future.

\section{REFERENCES}

1. Katz PO, Gerson LB, Vela MF. Guidelines for the diagnosis and management of gastroesophageal reflux disease. Am J Gastroenterol 2013 Mar;108(3):308-328. 
2. Fock KM, Talley N, Goh KL, Sugano K, Katelaris P,Holtmann G, Pandolfino JE, Sharma P, Ang TL, Hongo M, et al. Asia-Pacific consensus on the management of gastro-oesophageal reflux disease: an update focusing on refractory reflux disease and Barrett's oesophagus. Gut 2016 Sep;65(9):1402-1415.

3. Fass R. Proton-pump inhibitor therapy in patients with gastroesophageal reflux disease: putative mechanisms of alure. Drugs 2007;67:1521-1530.

4. You ZH, Perng CL, Hu LY, Lu T, Chen PM, Yang AC, Tsai SJ, Huang YS, Chen HJ. Risk of psychiatric disorders following gastroesophageal reflux disease: a nationwide populationbased cohort study. Eur J Intern Med 2015 Sep;26(7):534-539.

5. Cardin F, Ambrosio F, Amodio P, Minazzato L, Bombonato G, Schiff S, Finotti K, Giuliani D, Bianco T, Terranova C, et al. Quality of life and depression in a cohort of female patients with chronic disease. BMC Surg 2012 Nov;12(Suppl 1):S10.

6. Bakir S, Kinis V, Bez Y, Gun R, Yorgancilar E, Ozbay M, Aguloglu B, Meric F. Mental health and quality of life in patients with chronic otitis media. Eur Arch Otorhinolaryngol $2013 \mathrm{Feb} ; 270(2): 521-526$.

7. Eitner S, Wichmann M, Schlegel A, Holst S. Clinical study on the correlation between psychogenic dental prosthesis incompatibility, oral stereognosis, and the psychologic diagnostic tools SCL-90-R and CES-D. Int J Prosthodont 2007 Sep-Oct;20(5):538-545.

8. Levy RL, Olden K, Naliboff BD, Bradley LA, Francisconi C, Drossman DA, Creed F. Psychosocial aspects of the functional gastrointestinal disorders. Gastroenterology 2006 May;130(5):1447-1458.

9. Paice JA, Ferrell B. The management of cancer pain. CA Cancer J Clin 2011 May-Jun;61(3):157-182.

10. Derogatis LR, Lipman RS, Covi L. SCL-90: an outpatient psychiatric rating scale-preliminary report. Psychopharmacol Bull 1973 Jan;9(1):13-28.

11. Derogatis LR, Rickels K, Rock AF. The SCL-90 and the MMPI: a step in the validation of a new self-report scale. $\mathrm{Br}$ J Psychiatry 1976 Mar;128:280-290.

12. Bredenoord AJ, Fox M, Kahrilas PJ, Pandolfino JE, Schwizer W, Smout AJ, International High Resolution Manometry Working Group. Chicago classification criteria esophageal motility disorders defined in high resolution esophageal pressure topography. Neurogastroenterol Motil 2012 Mar;24(Suppl 1):57-65.

13. Mittal RK, Karstens A, Leslie E, Babaei A, Bhargava V. .Ambulatory high-resolution manometry, lower esophageal sphincter lift and transient lower esophageal sphincter relaxation. Neurogastroenterol Motil 2012 Jan;24(1):40-46.

14. Lim CH, Choi MG, Baeg MK, Moon SJ, Kim JS, Cho YK, Park JM, Lee IS, Kim SW, Choi KY. Symptom characteristics and psychosomatic profiles in different spectrum of gastroesophageal reflux disease. Gut Liver 2014 Mar;8(2):165-169.

15. Jansson C, Nordenstedt H, Wallanger MA, Johansson S, Johnsen R, Hveem K, Lagergren J. Severe gastro-oesophageal reflux symptoms in relation to anxiety, depression and coping in a population-based study. Aliment Pharmacol Ther 2007 Sep;26(5):683-691.

16. Lee YC, Wang HP, Chiu HM, Liao SC, Huang SP, Lai YP, Wu MS, Chen MF, Lin JT. Comparative analysis between psychological and endoscopic profiles in patients with gastroesophageal reflux disease: a prospective study based on screening endoscopy. J Gastroenterol Hepatol 2006 May;21(5):798-804.

17. Núñez-Rodríguez MH, Miranda Sivelo A. Psychological factors in gastroesophageal reflux disease measured by scl90-R questionnaire. Dig Dis Sci 2008 Dec;53(12):3071-3075.

18. Nozu T, Komiyama H. Clinical characteristics of asymptomatic esophagitis. J Gastroenterol 2008 Feb;43(1):27-31.

19. Neumann H, Monkemuller K, Kandulski A, Malfertheiner P. Dyspepsia and IBS symptoms in patients with NERD, ERD and Barrett's esophagus. Dig Dis Sci 2008 May;26(3):243-247.

20. Rey E, Elola-Olaso CM, Rodríguez-Artalejo F, Locke GR 3rd, Díaz-Rubio M. Prevalence of atypical symptoms and their association with typical symptoms of gastroesophageal reflux in Spain. Eur J Gastroenterol Hepatol 2006 Sep;18(9):969-975.

21. Lee SP, Lee KN, Lee OY, Lee HL, Choi HS, Yoon BC, Jun DW, Sohn W, Cho SC. The relationship between existence of typical symptoms and psychological factors in patients with erosive esophagitis. J Neurogastroenterol Motil 2012 Jul;18(3):284-290.

22. Robles PG, Brooks D, Goldstein R, Salbach N, Mathur S. Gender-associated differences in pulmonary rehabilitation outcomes in people with chronic obstructive pulmonary disease: a systematic review. J Cardiopulm Rehabil Prev 2014 Mar-Apr;34(2):87-97.

23. Baggio G, Corsini A, Floreani A, Giannini S, Zagonel V. Gender medicine: a task for the third millennium. Clin Chem Lab Med 2013 Apr;51(4):713-727.

24. Kotková P, Weiss P. Psychiatric factors related to sexual functioning in patients with Parkinson's disease. Clin Neurol Neurosurg 2013;115:419-424. 